\title{
A Escola Confessional Católica Romana
}

\author{
The Roma Catholic Confessional School
}

\section{Sérgio Rogério Azevedo Junqueira ${ }^{[a]}$, Valéria Andrade Lea[ ${ }^{[b]^{*}}$}

[a] Universidade Federal do Paraná (UFPR), Curitiba, PR, Brasil

[b] Pontifícia Universidade Católica do Paraná (PUCPR), Curitiba, PR, Brasil

\section{Resumo}

Com objetivo de assinalar a identidade e os princípios da Escola Confessional Católica Romana foi organizada uma pesquisa qualitativa documental elaborada a partir do magistério da Igreja Católica Romana, pois esta compreensão da confessionalidade é refletida na discussão sobre a educação na sociedade que se quer propor ou impor. A Escola Católica se entende como aquela que é dirigida pela autoridade eclesiástica competente ou por pessoa jurídica eclesiástica pública, ou que a autoridade eclesiástica reconhece como tal, pois a instrução e a educação nela devem fundamentar-se nos princípios da doutrina católica; os mestres devem distinguir-se pela retidão de doutrina e probidade de vida. Efetivamente a escola católica é convocada, por seu ambiente, a desenvolver atividades de instrução e aprendizagem que favoreçam valores propostos pelo Evangelho mesmo na pluralidade dos contextos culturais e na variedade das possibilidades educativas; quer colaborar na formação do respeito pela dignidade de cada pessoa e pela sua unicidade, visando o equilíbrio nos aspectos cognitivos, afetivos,

SRAJ: Doutor em Ciências da Educação, Pós-Doutor em Ciências da Religião, e-mail: srjunq@gmail.com VAL: Mestre em Teologia, e-mail: vandradeleal@yahoo.com.br 
sociais, profissionais, éticos, espirituais e buscando o encorajamento para que cada estudante possa desenvolver os próprios talentos, num clima de cooperação e de solidariedade; visa promover a pesquisa científica como empenho rigoroso em relação à verdade, com a consciência dos limites do conhecimento humano, mas também com uma grande abertura da mente e do coração; quer educar para o respeito pelas ideias, a abertura ao confronto, a capacidade de discutir e colaborar num espírito de liberdade e de atenção pela pessoa.

Palavras-chave: Educação. Educação Confessional. Escola Católica.

\section{Abstract}

In order to assess the identity and principles of the Roman Catholic Confessional School, a documentary qualitative research was organized, drawn from the Magisterium of the Roman Catholic Church as this understanding of confessionality is reflected in the discussions on education in the society it wants to propose or impose. The Catholic school is understood as the one directed by a competent ecclesiastical authority or public ecclesiastical legal person, or one an ecclesiastical authority recognizes as such, for the instruction and education at a Catholic school should be based on the principles of the Catholic doctrine; teachers are distinguished by the righteousness of doctrine and uprightness of their life. Therefore, the Catholic school is called because of its environment, to develop instruction and learning activities that promote the values proposed by the Gospel even in the plurality of cultural settings and in the variety of educational opportunities in order to collaborate in shaping the respect for the dignity of each person and their uniqueness, aiming to balance the cognitive, affective, social, professional, ethical and spiritual aspects. It aims to encourage each student to develop their talents in an atmosphere of cooperation and solidarity; as well as to promote scientific research and rigorous commitment to the truth, aware of the limits of human knowledge, but also with a great openness of mind and heart. It also seeks to educate its students to respect ideas, to be open to confrontation, to be able to discuss and collaborate in a spirit of freedom and care for people.

Keywords: Education. Denominational education. Catholic school. 


\section{Introdução}

Dentre as múltiplas identidades confessionais, este artigo se baseia em pesquisa realizada frente à problemática da identidade católica da escola diante da pluralidade e desafios da atualidade e se propõe a refletir sobre os fundamentos e a identidade da Escola Católica a primeira modalidade existente no Brasil a partir da ação missionária dos jesuítas. Trata-se de uma análise documental de alguns textos oficiais da Igreja Católica que orientam tais instituições de ensino no desenvolver de sua missão e que explicitam sua finalidade fundamentada na sua visão de pessoa e de mundo. Embora já conhecidos, os textos da Congregação para a Educação Católica apresentam-se como balizadores para as escolas católicas que precisam continuamente voltar às fontes para não perderem seu fulcro diante dos novos desafios.

Desde Platão, diversos pensadores reconheceram a importância da educação para o processo de formação a partir do modelo de sociedade que se quer propor ou impor. Desta forma, a educação formal, em âmbito civil, visa primordialmente à inserção da pessoa na sociedade, apta para o mundo do trabalho e as relações sociais, mediante a transmissão do conhecimento construído e acumulado pelas gerações precedentes. Tal se dá na escola, que é o espaço de encontro e socialização cultural (XAVIER, 2012, p. 195).

Embora diversos sistemas de ensino defendam a laicidade da escola, ao promover o intercâmbio cultural não é possível prescindir do aspecto religioso presente nos diversos contextos e que torna inviável qualquer projeto laicista. Para alguns grupos, entretanto, a educação se apresenta como uma das estratégias principais no processo de transmissão, propagação e proteção dos sistemas religiosos. São estas as escolas confessionais, vinculadas ou pertencentes a igrejas ou confissões religiosas, baseadas em princípios, objetivos e forma de atuação de uma religião, diferenciando-se, portanto, das escolas laicas. Para esse tipo de escola, o desenvolvimento dos sentimentos religioso e moral nos estudantes é o objetivo primeiro do trabalho educacional. Dessa forma, se a escola leiga constrói sua proposta baseada apenas em correntes pedagógicas, a confessional procura ter um embasamento filosófico-teológico. 
A confessionalidade perpassa toda estrutura administrativa e o projeto acadêmico da instituição: em seu estatuto, em sua ética, na presença e atuação da pastoral ou estudos de textos sagrados extracurriculares, nas disciplinas e no seu objetivo de formação integral da pessoa. Entretanto, ser confessional não pressupõe fazer proselitismo ou impor as convicções religiosas aos estudantes, professores e funcionários. A sociedade hoje vive a pluralidade, a liberdade religiosa e o respeito às crenças individuais. Uma escola confessional busca testemunhar e expor, mas não impor sua fé. Ensinar a viver entre as diferenças, acolhendo-as e valorizando-as, é tarefa da escola confessional, sabendo distinguir e conciliar culturas, ciência e fé.

\section{Escola Católica}

Como Escola Católica entende-se aquela que é dirigida pela autoridade eclesiástica competente ou por pessoa jurídica eclesiástica pública, ou que a autoridade eclesiástica reconhece como tal, mediante documento (Código de Direito Canônico can. 803 §1). A instrução e a educação na Escola Católica fundamentam-se nos princípios da doutrina católica; "os mestres devem distinguir-se pela retidão de doutrina e probidade de vida” (Código de Direito Canônico can. 803 §2). Nenhuma escola pode usar o título de Católica sem o consentimento da autoridade eclesiástica competente.

A Escola Confessional Católica nasce com a pretensão de ser parte da missão da Igreja; como meio privilegiado para a formação integral do ser humano. Portanto, é parte integrante da missão da Igreja e lugar de evangelização, de autêntico apostolado e de ação pastoral.

[...] A presença da Igreja no setor escolar manifesta-se com especial evidência através da escola católica. Não menos que as demais escolas, visa ela os fins culturais e a formação humana dos jovens. É, porém, característica sua criar uma atmosfera de comunidade escolar animada pelo espírito evangélico da liberdade e da caridade, auxiliar os adolescentes a que no desdobramento da personalidade também cresçam segundo a nova criatura que se tornaram pelo batismo [...] (GE 8). 
Em geral, antes do Concílio Vaticano II, a escola servia à "sociedade perfeita”, na qual se inscreviam os que seriam salvos. Após o Concílio, a escola católica adquiriu novo estatuto. Deixou de ser restrita e assumiu de fato uma perspectiva católica, no sentido próprio do termo, isto é, aberta a todos que a escolham e acentuem o caráter específico de seu projeto educativo. No já citado texto, Gravissimum Educationis (GE), a Igreja Católica justifica seu compromisso com a educação em face à preocupação com o ser humano integral.

Visto que a santa Mãe Igreja, para realizar o mandato recebido do seu fundador, de anunciar o mistério da salvação a todos os homens e de tudo restaurar em Cristo, deve cuidar de toda a vida do homem, mesmo da terrena enquanto está relacionada com a vocação celeste, tem a sua parte no progresso e ampliação da educação (GE Proêmio).

No texto, a Igreja Católica reconhece a educação como direito inalienável, por isso, deseja contribuir não apenas para um grupo específico de fiéis, mas para toda pessoa humana. A propósito, cabe lembrar que, segundo a fé católica, a salvação é oferecida a toda a humanidade, por isso, a missão de anunciar a salvação é inerente ao ser da Igreja. Tal reflexão leva em conta as diferenças entre culturas e povos e a urgente necessidade de promover, por meio da educação, o diálogo entre pessoas e países diferentes.

Todos os homens, de qualquer estirpe, condição e idade, visto gozarem da dignidade de pessoa, têm direito inalienável a uma educação correspondente ao próprio fim, acomodada à própria índole, sexo, cultura e tradições pátrias, e, ao mesmo tempo, aberta ao consórcio fraterno com os outros povos, para favorecer a verdadeira unidade e paz na terra. A verdadeira educação, porém, pretende a formação da pessoa humana em ordem ao seu fim último e, ao mesmo tempo, ao bem das sociedades de que o homem é membro e em cujas responsabilidades, uma vez adulto, tomará parte.

[...] Além disso, de tal modo se preparem para tomar parte na vida social, que, devidamente munidos dos instrumentos necessários e oportunos, sejam capazes de inserir-se ativamente nos vários agrupamentos da comunidade humana, abram-se ao diálogo com os outros e se prontifiquem a trabalhar pelo bem comum (GE 1). 
A ação educativa católica pretende ser integral considerando "as qualidades físicas, morais e intelectuais, e à aquisição gradual dum sentido mais perfeito da responsabilidade com a própria vida, retamente cultivada com esforço contínuo e levada por diante na verdadeira liberdade" (GE 1). Para tanto, busca que o conteúdo da educação, "patrimônio da humanidade" (GE 4), esteja articulado com a fé, visto que todo espaço católico é lugar de anúncio do Cristo Ressuscitado. A escola católica educa para que a vida em sociedade seja vivida a partir dos valores do Evangelho, partindo da experiência destes valores no interior da própria da escola. Assim, todos os educadores católicos, mesmo os que não atuam nas escolas confessionais, são chamados a ser testemunha de fé e coerência com os princípios cristãos (GE 7).

A declaração conciliar $G E$ abre horizontes para os católicos que, de alguma forma, dedicam-se à educação, na Escola Católica ou não. As instituições afins, no entanto, são espaços privilegiados para a ação da Igreja Católica neste campo e meio pelo qual ela pode desenvolver sua missão de ser testemunha da caridade de Cristo. Com a leitura do texto, entende-se que a Escola Católica é parte da Igreja e como tal, partilha de sua missão evangelizadora e tenciona ser sinal e presença de Cristo no mundo.

Outro importante documento que assinala a identidade da escola católica foi publicado em 1977, com base às reflexões feitas no Concílio. Intitulado Escola Católica, o texto lança as diretrizes para que as conferências episcopais elaborem seu "projeto educativo que corresponda às exigências da educação integral dos jovens" (Escola Católica 4), tendo em vista as diferenças locais e as leis dos Estados.

A instituição educacional católica procura "garantir a presença do pensamento cristão" (Escola Católica 11) na sociedade plural, bem como levar o jovem a "viver coerentemente às exigências do batismo", inserindose e formando comunidades cristãs autênticas (Escola Católica 12). Quer também contribuir com o diálogo cultural tendo em vista a formação integral de cada pessoa (Escola Católica 14-15). O documento indica que a Igreja Católica, além de ver na escola um espaço de evangelização, quer atuar de forma cooperativa com outras instâncias que visam o desenvolvimento da sociedade em todos os âmbitos. 
Nesta perspectiva cabe à Escola Católica um lugar próprio na organização escolar das diversas nações, tendo em conta as modalidades e possibilidades dos vários contextos ambientais. Oferecendo essa alternativa, a Igreja propõe-se responder às exigências de cooperação, que hoje se manifestam num mundo caracterizado pelo pluralismo cultural, e contribui para promover a liberdade de ensino, de modo que se tutele e garanta a liberdade de consciência e o direito dos pais a escolherem a escola que melhor corresponda aos seus propósitos educativos (Escola Católica 14).

Como a qualquer outra escola, cabe-lhe "salientar a dimensão ética e religiosa da cultura" (Escola Católica 30), agindo em cooperação com as demais instâncias sociais a fim de capacitar para a "escolha de valores de vida" (Escola Católica 32), "formar personalidades fortes e responsáveis, capazes de opções livres e acertadas" (Escola Católica 31). Sendo isso tarefa de toda e qualquer instituição de ensino, entende-se que o diferencial da escola católica está em que ela "define-se precisamente pela referência explícita ao Evangelho de Jesus Cristo, que deve radicar-se na vida e na consciência dos fiéis" (Escola Católica 9).

Assim, a Escola Católica encontra sua missão específica na própria missão da Igreja a que pertence de conduzir à salvação, que é Jesus Cristo. A concepção cristã do mundo e da realidade é a grande diferença desta instituição em relação às demais. A catolicidade da escola se dá por sua centralidade na pessoa de Jesus Cristo, seus ensinamentos, seu jeito de viver, que é aberto para estabelecer relação com todos. Esse foco não pode ser abdicado, pois, "sem a referência constante à Palavra e sem o renovado encontro com Cristo, a Escola Católica perde o seu fulcro" (Escola Católica 55). A Escola Católica é, antes de tudo, escola cristã, pois não está a anunciar a Igreja Católica, mas a quem esta anuncia. Assim como a Igreja, a Escola Católica deve transmitir, além do patrimônio cultural, a fé em Jesus Cristo, mostrando como segui-Lo rumo ao Pai. O Evangelho é, então, manual básico da comunidade educativa católica, formada por pais, professores, pedagogos e demais profissionais atuantes na escola (LEAL, 2014, p. 63).

Este projeto educativo cumpre-se na comunidade escolar, da qual fazem parte todos aqueles que são diretamente ligados a ele: os professores, a direção administrativa e auxiliar, os genitores — figuras centrais, uma vez que naturais e insubstituíveis educadores dos próprios 
filhos - e os estudantes, coparticipantes e corresponsáveis como verdadeiros protagonistas e sujeitos ativos do processo educativo.

No projeto educativo da Escola Católica é Cristo o fundamento. Ele revela e promove o sentido novo da existência e transforma-a, habilitando o homem a viver de maneira divina, isto é, a pensar, querer e agir segundo o Evangelho, fazendo das bem-aventuranças a norma da vida [...] (Escola Católica 34).

A sala de aula pode ser considerada ponto de partida e de chegada da evangelização escolar, pois, através dos conteúdos curriculares, propõe-se aos estudantes uma visão cristã do mundo, de ser humano e, sobretudo, uma experiência de Deus. É neste espaço, que se viabiliza uma leitura de mundo com sensibilidade para que percebam os sinais de vida e de morte, a partir do referencial presente nos valores evangélicos. Entretanto, é importante ressaltar que a evangelização escolar não se limita à sala de aula. Ela exige uma profunda dinamicidade, que envolva os estudantes, as famílias, o corpo docente, técnico e todos os funcionários. Enfim, é preciso que todo o pessoal envolvido em uma Escola Católica contribua para ser sinal de vida, numa comunicação permanente da proposta do Cristo, que se encarnou, morreu e ressuscitou por toda a humanidade.

Também no Código do Direito Canônico, promulgado em 1983, encontram-se algumas orientações para a educação:

Sendo que a verdadeira educação deve promover a formação integral da pessoa humana, em vista de seu fim último e, ao mesmo tempo, do bem comum da sociedade, as crianças e jovens sejam educados de tal modo que possam desenvolver harmoniosamente seus dotes físicos, morais e intelectuais, adquirir senso de responsabilidade mais perfeito e correto uso da liberdade, e sejam formados para uma participação ativa na vida social (Código de Direito Canônico can. 795).

É direito da Igreja criar e dirigir escolas de qualquer disciplina, ordem e grau (Código de Direito Canônico can. 800, §1).

Os Institutos religiosos, que têm a educação como missão própria, conservando fielmente esta sua missão, procurem dedicar-se à educação católica, também por suas escolas fundadas com o consentimento do Bispo (Código de Direito Canônico can. 801).

Está sujeita à autoridade da Igreja a formação religiosa católica que se ministra em quaisquer escolas, ou que se promove pelos diversos meios 
de comunicação social; compete à Conferência dos Bispos traçar normas gerais nesse campo de ação, e ao Bispo diocesano compete organizá-lo e supervisioná-lo (Código de Direito Canônico can. 804).

Todas essas orientações e normatizações do Código de Direito Canônico favorecem a compreensão da função evangelizadora de uma Escola Católica. O discurso sobre este espaço caracteriza-se como instituição social e responsável pelo processo contínuo de socialização, como o lugar por excelência para formar o ser humano.

\section{Educação Confessional na perspectiva da Igreja latino-americana}

A partir das reflexões feitas no Concílio Vaticano II, com ares de descentralização, coube às conferências episcopais analisar e encontrar formas de colocar em práticas seus propósitos nas distintas realidades. Na América Latina, a conferência em Medellín (1968), da qual surgiu o documento de mesmo nome, lança as bases para o novo jeito de pensar e ser Igreja, assim como para a educação.

Particularmente em Medellín (1968), inaugura-se oficialmente uma forma de ver e pensar a Igreja Católica a partir do próprio contexto e da questão social, dada a realidade dos povos latinos na América, donde surge a chamada teologia da libertação. Esta, ao contrário do que possa parecer, não reduz o conceito de salvação a questões sociais, mas procura ter uma visão global da pessoa, sendo peça chave na ação pastoral e na educação (LEAL, 2014, p. 41).

A perspectiva de educação evocada em Medellín apresenta as seguintes características: uma educação que transforma o educando em sujeito de seu próprio desenvolvimento; que não seja apenas catequética, mas integral do ser humano; criativa, porquanto deseja antecipar o novo tipo de sociedade que se procura na América latina; para uma escola aberta ao diálogo e acessível aos setores mais amplos da sociedade (democratização); educação crítica, sistemática e assistemática, a serviço da comunidade local e nacional; uma educação que integra as particularidades nacionais no contexto mais amplo do Continente e do mundo; enfim, uma educação, na comunidade educativa. Assim, compete à escola católica: 
Ser uma verdadeira comunidade formada por todos os elementos que a integram; integrar-se na comunidade local e estar aberta à comunidade nacional e latino-americana; ser dinâmica, viva e estar em contínua experimentação franca e leal; estar aberta ao diálogo ecumênico; partir da escola para a comunidade, transformando a mesma escola em centro cultural, social e espiritual da comunidade; partir dos filhos para chegar aos pais e à família; partir da educação escolar para chegar aos demais ambientes educacionais (Medellín, p. 55).

Onze anos mais tarde, a Conferência dos Bispos latino-americanos realizada em Puebla confirma as posições teológicas de Medellín e ressalta a necessidade de promover uma educação libertadora. Considerando que educar não é transmitir aos outros a forma de ser humano. É, ao contrário, o esforço de cada um para fazer-se humano. O ser humano se educa; o educando é sujeito de seu próprio desenvolvimento. Cada pessoa é agente de seu desenvolvimento e por ele responsável. Importa ressaltar que, em Puebla, se insistiu que o ser humano é também sujeito do desenvolvimento social.

O fato é que a educação, em suas diversas formas e níveis, não existe isoladamente. Ela faz parte do contexto social em que está inserida. Por isso mesmo, não se pode esperar que a educação conseguisse significativos resultados a serviço da fraternidade, se no restante da sociedade continuar prevalecendo a não fraternidade, o individualismo, a valorização do lucro acima da pessoa humana. No processo de transformação em vista de uma nova sociedade, a educação tem um importante papel na caminhada de ajudar os seres humanos a passar de condições de vida menos humanas para condições mais humanas, contando também com a soma das forças de todas as instâncias sociais.

A educação contribui para despertar a capacidade crítica das pessoas, condição indispensável para a renovação da sociedade; a capacidade de ver as causas reais e sociais da injustiça que impede a fraternidade. $\mathrm{O}$ objetivo principal dessa educação para a justiça consiste no esforço em despertar a consciência a fim de reconhecer as situações que carecem de transformação, ser uma experiência concreta, continuada e pluriforme de participação e comunhão, vivida na colaboração mútua de pessoas livres, incentivar a criatividade em vista da nova sociedade que buscamos para América Latina. Nesta perspectiva a educação católica precisa produzir 
os agentes de transformação permanente e orgânica que a sociedade da América Latina requer:

- Integrar-se na comunidade local e estar aberta à comunidade nacional e Latino-Americana — Medellín, Educação III, 2-4";

- Promover o diálogo real entre as pessoas, e entre a ciência, a cultura e a fé - Medellín, Educación III, 03.02 / Puebla, n. 1039-1240;

- A educação libertadora deve ser aberta ao diálogo para se enriquecer com os valores que a juventude intui e descobre como válidos para o futuro, e assim promover a compreensão dos jovens entre si e com os adultos - Medellín, Educação II, 1;

- Converter o educando em sujeito e colaborar para que aqueles que hoje não têm voz, porque foram reduzidos ao silêncio, comecem a fazer ouvir suas próprias palavras. Buscar uma educação de base, que não vise somente à alfabetização, mas que o educando se torne consciente de seu desenvolvimento integral. Converter o educando em sujeito, não só de seu próprio desenvolvimento, mas também posto a serviço do desenvolvimento da comunidade: educação para o serviço (Puebla, n. 1030).

Com essas características, inspirando-se em Jesus Cristo que é a verdade e anunciando-o explicitamente, a educação se tornará evangelizadora e, portanto, libertadora.

A educação evangelizadora assume e completa a noção de educação libertadora, porque contribui para a conversão do ser humano total, orientando-o radicalmente para a genuína libertação cristã, que torna o ser humano acessível à plena participação no mistério de Cristo ressuscitado, isto é, à comunhão filial com o Pai e à comunhão fraterna com todos os seres humanos, seus irmãos.

Urge uma verdadeira formação cristã sobre a vida, envolvida nas dimensões do ser humano, que corrija os desvios de certas informações que se recebe na sociedade; uma educação para a liberdade, um dos valores fundamentais da pessoa. É também necessário que a educação cristã se preocupe em educar para o trabalho, especialmente nas circunstâncias da cultura atual.

Em 1992, a conferência em Santo Domingo ratificou muitos dos posicionamentos das anteriores. O conceito de educação como "assimilação da cultura" é confirmado, mas ressalta-se a transmissão e 
assimilação da cultura cristã e "a inculturação do Evangelho na própria cultura” (Santo Domingo 263).

Nossos compromissos no campo educacional se resumem, sem dúvida, à linha pastoral da inculturação: a educação é a mediação metodológica para a evangelização da cultura. Portanto, pronunciamo-nos por uma educação cristã desde e para a vida no âmbito individual, familiar e comunitário e no âmbito do ecossistema; que fomente a dignidade da pessoa humana e a verdadeira solidariedade; educação a ser integrada por um processo de formação cívico-social inspirado no Evangelho e na Doutrina Social da Igreja. Comprometemonos com uma educação evangelizadora (Santo Domingo 271).

De forma geral, a ênfase recai sobre o caráter confessional, na centralidade da pessoa de Jesus Cristo, e situa a escola católica na linha da "nova evangelização" proposta por João Paulo II.

Aúltima conferência aconteceu em Aparecida, 2007. Seu documento final constata um cenário religioso que pede "conversão pastoral, que implica escutar com atenção e, discernir 'o que o Espírito está dizendo às Igrejas' (Ap 2,29), através dos sinais dos tempos em que Deus se manifesta" (Aparecida n. 366). Trata-se de um apelo à missionaridade de todos os batizados para que todos possam experimentar um "encontro pessoal e comunitário com Jesus Cristo" (Aparecida n. 11).

Os bispos também percebem a necessidade de preparar leigos missionários e solicita que "os melhores esforços das paróquias, nesse início do terceiro milênio, estejam na convocação e na formação de leigos missionários" (Aparecida n. 174). A Escola Católica é apresentada como um dos lugares desta formação (Aparecida n. 328-340).

Confirma-se em Aparecida o compromisso com a educação integral, para autonomia e liberdade. Porém se constata o "reducionismo antropológico, que concebe a educação preponderantemente em função da produção, da competitividade e do mercado" (Aparecida n. 328). Diante disso, os bispos reafirmam o direto de todos à educação de qualidade, humanizadora.

A educação humaniza e personaliza o ser humano quando consegue que este desenvolva plenamente seu pensamento e sua liberdade, fazendo-o frutificar em hábitos de compreensão e em iniciativas de comunhão com a totalidade 
da ordem real. Dessa maneira, o ser humano humaniza seu mundo, produz cultura, transforma a sociedade e constrói a história (Aparecida n. 330).

De forma geral, a escola confessional católica na América Latina, em face à realidade, é chamada a inserir-se na sociedade, olhando, julgando e agindo para formar agentes transformadores da realidade mediante a vivência dos valores do Evangelho. Como para toda a Igreja, a educação integral para todos, humanizadora e promotora da liberdade e autonomia compõe o múnus de todas as instituições educacionais católicas.

A análise dos documentos citados mostra com clareza que às instituições educacionais de confissão católica compete a fidelidade ao Evangelho, a formação integral, a valorização do patrimônio cultural, a transformação da realidade e o anúncio explícito da Palavra de Deus. Para tal, necessita organizar seu projeto pedagógico sem perder a dimensão evangelizadora de sua ação educativa.

\section{Escola católica e contexto multicultural: desafios e perspectivas atuais}

A instituição escolar, independentemente de ser católica ou não, é interpelada pelo contexto sociocultural do momento, o que exige discernimento para buscar uma resposta adequada às questões da atualidade. No atual contexto se lida com um forte pluralismo social que incide de maneira especial no campo educacional, ao ficar descartado um sistema único de pensamento, ao ser questionada a hierarquia única de valores, ao se multiplicarem indefinidamente as ofertas de compreensão do mundo e orientações para a vida. De fato, o pluralismo social, com incontestáveis aspectos positivos, vem favorecendo o cultivo de um relativismo constante, produzindo um "pensamento frágil" e uma "religião da moda", uma indefinição na maneira de viver e a rejeição às opções que conduzem a vida a uma determinada direção.

A autêntica educação, no entanto, visa ao aprimoramento da pessoa humana em relação a seu fim último e o bem das sociedades de que o ser humano é membro, em cujas tarefas, uma vez adultas, terá que participar.

De acordo com os progressos da psicologia, da pedagogia e da didática, há de dar-se assistência às crianças e aos jovens para desenvolverem harmoniosamente seus potenciais físicos, morais e intelectuais, para 
adquirirem gradativamente um senso mais perfeito de responsabilidade, que há de ser retamente desenvolvido na própria existência por contínuo esforço e verdadeira liberdade, superados os obstáculos com generosidade e constância. De acordo com a idade, sejam preparados por uma educação sexual positiva e prudente. Além disso, perfeitamente equipados com os instrumentos necessários e oportunos, estejam habilitados a entrosar-se ativamente nos diversos grupos da comunidade humana, abrindo-se, com gosto, no esforço de promover o bem comum (GS 1).

O Concílio Vaticano II ponderava a importância da escola, enumerando algumas de suas funções:

Entre todos os instrumentos da educação, possui a escola importância peculiar. É por força de sua missão que ela aperfeiçoa, com desvelo ininterrupto, as faculdades intelectuais, desenvolve a capacidade de julgar com retidão, faz participar no patrimônio da cultura adquirido por gerações passadas, promove o sentido dos valores, prepara a vida profissional, faz nascer relações de amizade entre os alunos de índole e condições diversas e, assim, favorece a disposição mútua de se compreenderem (GS 5).

O desafio pelo qual se sente interpelada a escola católica neste contexto pluralista não se reduz a ensinar a liberdade, tarefa essencial em sua missão educativa, mas inclui o estabelecer uma coerência de vida a partir de todo o projeto educativo, dos valores que ele proclama, de ajudar os estudantes a edificar sua própria identidade. Simultaneamente, tem a tarefa de educar para a tolerância, para o respeito e para a cooperação, pois ninguém é possuidor de toda a verdade.

A escola não pode ser pensada separadamente das outras instituições da educação nem conduzida como corpo à parte, mas deve relacionar-se com o mundo da política, da cultura e com a sociedade em conjunto. Compete à escola católica enfrentar com determinação a nova situação cultural, colocar-se como instância crítica dos projetos de educação parciais, exemplo e estímulo para as outras instituições de educação, tornar-se fronteira avançada da preocupação educativa da comunidade eclesial [...] (A Escola Católica no Limiar do Terceiro Milênio n. 16). 
O reconhecimento da pluralidade na qual está inserido o projeto educativo católico e com a qual é convidado a dialogar tem encontrado ressonância crescente nos pronunciamentos do magistério da Igreja para Educação Católica. O pluralismo cultural, que tem o intercâmbio religioso como elemento inevitável, é fato verificável e representa simultaneamente um dom e um desafio a ser assumido. Desafio a fazer possível a convivência entre as distintas expressões cultuais e promover um diálogo que favoreça uma sociedade pacífica.

Considerando sua natureza religiosa expressa pela confessionalidade, esta tarefa se amplia para a aproximação e integração dialógica com as demais espiritualidades e tradições religiosas. Antes de ser uma exigência que brota da conjuntura vigente, este pressuposto corresponde a um princípio de diálogo entre culturas e credos que estão no cerne das próprias confissões religiosas. O diálogo não só se fundamenta nem objetiva simplesmente uma especulação científica e fenomenológica, mas é exigência em nome de uma convivência mais pacífica e respeitosa neste espaço escolar e também na sociedade. Essa missão é assumida pela Escola Católica que busca "promover o encontro entre os diferentes ajuda a compreender-se reciprocamente, sem que isso suponha renunciar à sua própria identidade" (Educare al Dialogo Interculturale nella Scuola Cattolica: Introduzione, tradução livre). Para ela,

A razão para o diálogo com pessoas de outras religiões e comunidades reside no fato de que todos nós somos criaturas de Deus, que age em cada pessoa humana que através da razão, percebe o mistério de Deus e reconhece os valores universais (Educare al Dialogo Interculturale nella Scuola Cattolica n. 13; tradução livre).

Assim, entende-se que ao abrir-se ao diálogo a escola confessional reafirma sua identidade de oferecer "educação verdadeiramente personalista na esteira da cultura e tradição humanística cristã” (Educare al Dialogo Interculturale nella Scuola Cattolica n. 46; tradução livre) e contribui na formação para o diálogo em um mundo pluralista, sobretudo neste momento significativo da história, em que as instituições são desafiadas a repensar sua atuação coerente num mundo plural.

A Escola Católica possui um papel social e eclesial: busca a formação do ser humano integral, apoiada nos valores do Evangelho proclamados e vividos. 
É "por sua própria vocação, intercultural" (Educare al Dialogo Interculturale nella Scuola Cattolica n. 61; tradução livre) e sabe de sua responsabilidade, sua identidade e como agir em meio à diversidade. Ao anunciar o Evangelho de Jesus Cristo sua prioridade é a pessoa humana, particularmente os mais vulneráveis. À medida que aprofunda essa consciência, pode tornar-se cada vez mais um sinal de vida e de esperança para a sociedade em que está inserida.

\section{Considerações finais}

Efetivamente a escola católica é convocada, por seu ambiente, a desenvolver atividades de instrução e aprendizagem que favoreçam valores propostos pelo Evangelho, mesmo na pluralidade dos contextos culturais e na variedade de possibilidades educativas, que colaborem na formação do respeito pela dignidade de cada pessoa e pela sua unicidade, visando o equilíbrio nos aspectos cognitivos, afetivos, sociais, profissionais, éticos, espirituais; visando o encorajamento para que cada estudante possa desenvolver os próprios talentos, num clima de cooperação e de solidariedade, assim como a promoção da pesquisa científica como empenho rigoroso em relação à verdade, com a consciência dos limites do conhecimento humano, mas também com uma grande abertura da mente e do coração; para o respeito pelas ideias, a abertura ao confronto, a capacidade de discutir e colaborar num espírito de liberdade e de atenção pela pessoa.

Esta escola católica no século XXI é instada a discutir continuamente sua identidade para responder aos novos desafios e simultaneamente dialogar com os novos contextos. Para tanto, os últimos documentos da Congregação para Educação Católica, bem como eventos que discutem a educação confessional desta denominação, retomam aspectos das discussões desde a Gravissimum Educationis (GE) e desafiam a propor perspectivas frente à pluralidade e aos novos contextos sociais. Desta forma, concluir este artigo é rever o percurso, mas simultaneamente abrir perspectivas para a elaboração de um plano educativo evangelizador que seja posto em prática e que realize o projeto da Escola Católica em sua verdadeira identidade. 


\section{Referências}

CONCÍLIO ECUMÊNICO VATICANO II, 1962-1965, Cidade do Vaticano. Constituição Pastoral Gaudium et Spes: sobre a Igreja no mundo atual. In: COSTA, L. (Coord. Geral). Documentos do Concílio Ecumênico Vaticano II. 4. ed. São Paulo: Paulus, 2007. p. 539-661.

CONCÍLIO ECUMÊNICO VATICANO II, 1962-1965, Cidade do Vaticano. Declaração Gravissimum Educationis: sobre a educação cristã. In: COSTA, L. (Coord. Geral). Documentos do Concílio Ecumênico Vaticano II. 4. ed. São Paulo: Paulus, 2007. p. 321-338.

CONFERÊNCIA GERAL DO EPISCOPADO LATINO-AMERICANO E DO CARIBE, 2., 1968. Conclusões de Medellín. 2. ed. São Paulo: Paulinas, 1975.

CONFERENNCIA GERAL DO EPISCOPADO LATINO-AMERICANO E DO CARIBE, 3., 1979. Puebla: a evangelização no presente e no futuro da América Latina. Petrópolis: Vozes, 1979.

CONFERÊNCIA GERAL DO EPISCOPADO LATINO-AMERICANO E DO CARIBE, 4., 1992. Santo Domingo: Nova Evangelização, promoção humana, cultura cristã. Petrópolis: Vozes, 1992.

CONFERENNCIA GERAL DO EPISCOPADO LATINO-AMERICANO E DO CARIBE, 5., 2007. Documento de Aparecida. 5. ed. São Paulo: Paulinas / Paulus; Brasília: CNBB, 2008.

CONGREGAÇÃO PARA EDUCAÇÃO CATÓLICA. A Escola Católica no limiar do terceiro milênio [ECTM]. Disponível em: 〈http://www.vatican.va/roman_curia/ congregations/ccatheduc/documents/rc_con_ccatheduc_doc_27041998_school2000_po.html>. Acesso em: 6 ago. 2013.

CONGREGAÇÃO PARA EDUCAÇÃO CATÓLICA. Educare al dialogo interculturale nella scuola cattolica [EDI]. Vivere insieme per una civiltà dell'amore. Disponível em: <http:// www.vatican.va/roman_curia/congregations/ccatheduc/documents/rc_con_ccatheduc_doc_20131028_dialogo-interculturale_it.html>.Acesso em: 12 dez. 2014. 
CONGREGAÇÃO PARA EDUCAÇÃO CATÓLICA. Escola Católica [EC]. Disponível em: <http://www.vatican.va/roman_curia/congregations/ccatheduc/documents/rc_con_ ccatheduc_doc_19770319_catholic-school_po.html>. Acesso em: 29 jul. 2010.

JOÃO PAULO II (promulgação). Código de Direito Canônico. Promulgado por João Paulo II, Papa. São Paulo: Loyola, 2001.

LEAL, V. Pastoral e Evangelização Juvenil: o lugar da palavra de Deus. Dissertação (Mestrado em Teologia) — Pontifícia Universidade Católica do Paraná, Curitiba, 2014.

XAVIER, D. A educação como missão da Igreja no Magistério eclesial. In: FIGUEIRA, E.; JUNQUEIRA, S. Teologia e Educação: educar para a caridade e a solidariedade. São Paulo: Paulinas, 2012.

Recebido: 03/04/2016

Received: 04/03/2016

Aprovado: 09/06/2016

Approved: 06/09/2016 